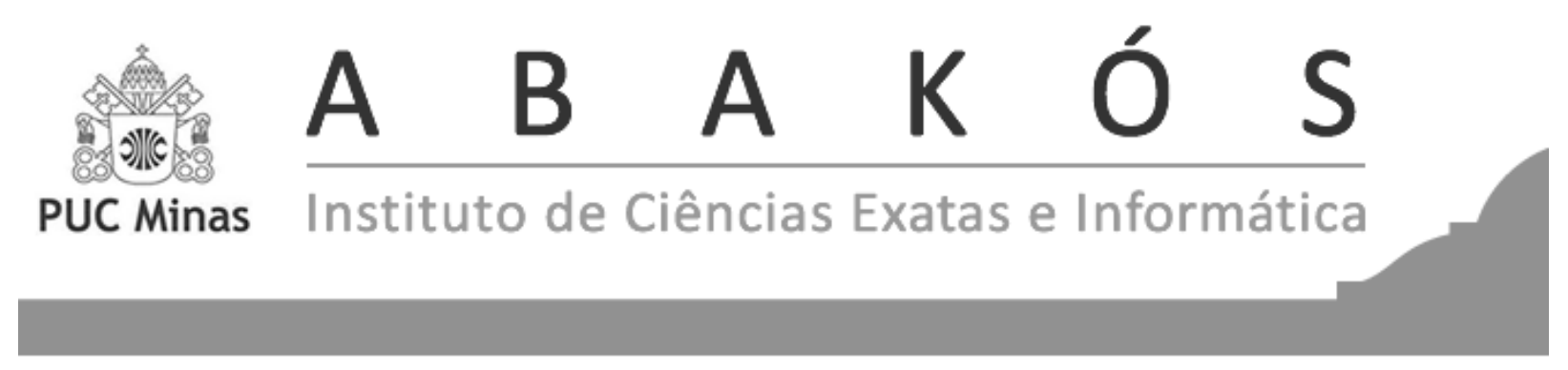

\title{
O Conhecimento Pedagógico e a Integração das Tecnologias de Informação no Ensino de Quadriláteros*
}

The Pedagogical Knowledge and the Integration of Information Technologies in the Teaching of Quadrilaterals

\section{Janaína Xavier de Almeida ${ }^{1}$ \\ Carmen Vieira Mathias ${ }^{2}$}

\begin{abstract}
Resumo
Com o estudo proposto, objetivou-se analisar e compreender as concepções matemáticas dos professores e, a partir disso, proporcionar oportunidades de introduzir a utilização das Tecnologias de Informação e Comunicação (TIC) como ferramentas auxiliares na prática docente, no ensino de quadriláteros. Essa compreensão utilizou como subsídios teóricos os Saberes Docentes, os conhecimentos do conteúdo específico e o conhecimento tecnológico e pedagógico do conteúdo. A pesquisa foi desenvolvida em duas etapas. Na primeira, foram realizadas entrevistas e aplicados questionários aos professores, atuantes nos anos iniciais do Ensino Fundamental, na rede Pública de um município do Rio Grande do Sul. Na segunda etapa, foi organizada uma Oficina de Formação Continuada, oferecida aos professores pesquisados. A partir da análise e discussão das etapas, constatou-se que os sujeitos da pesquisa se mostraram conscientes da importância do ensino de quadriláteros e do uso de TIC nos anos iniciais do ensino fundamental. Entretanto, essa consciência esbarra em dificuldades decorrentes da sua formação inicial e continuada.
\end{abstract}

Palavras-chave: Saberes Docentes. Tecnologias. Geometria. Formação de Professores.

\footnotetext{
* Submetido em 05/04/2017 - Aceito em 25/09/2017

${ }^{1}$ Professor do Estado do Rio Grande do Sul, Programa de Pós-graduação em Educação Matemática e Ensino do Física - UFSM, Brasil- janinha.05@ hotmail.com

${ }^{2}$ Professor Adjunto do Departamento de Matemática - UFSM, Programa de Pós-graduação em Educação Matemática e Ensino do Física - UFSM, Brasil- carmen@ufsm.br.
} 


\begin{abstract}
The proposed study aimed to analyze and understand the mathematical concepts of teachers and, from that, provide opportunities to introduce the use of Information and Communication Technologies (ICTs) as an important tool in the teaching practice, in the teaching of quadrilaterals. This understanding used as theoretical support the Teachers Knowledge, knowledge of the specific content and the technological pedagogical content knowledge. The research was developed in two stages. In the first one, interviews and questionnaires were applied to teachers of initial years of the Public School Network, in a city in the state of Rio Grande do Sul. In the second stage, it was organized a Continuing Training Workshop offered to the surveyed teachers. As of the analysis and discussion from the accomplishment of the stages, it was found that the subjects were aware of the importance of the teaching of quadrilaterals and the use of ICT in the early years of elementary school. However, this awareness ends up in difficulties arising from their initial and continuing education.
\end{abstract}

Keywords: Teachers Knowledge. Technologies. Geometry. Teacher Training. 


\section{INTRODUÇÃO}

A aprendizagem, em especial a aprendizagem matemática, necessita de uma percepção do cotidiano das pessoas e, além disso, deve ultrapassar as paredes da escola. Ela requer dos jovens uma postura de enfrentamento de situações, ao mesmo tempo em que demanda, por parte desses jovens, conhecimentos e técnicas para que possam utilizá-la. Portanto, acreditasse que são necessárias várias maneiras de planejamento e de execução, além de discussões de ideias e produção de argumentos para a solução de problemas. Porém, nesse âmbito, percebe-se que a escola e os processos de ensino têm caminhado mais lentamente do que a tecnologia. A compreensão das tecnologias digitais, na escola, especialmente em sala de aula, contribui para diagnosticar as suas possíveis implicações nas práticas docentes e suas potencialidades como ferramentas de construção do conhecimento. Nesse sentido, destaca-se que a prática docente é uma prática carregada do saber incorporado pelo professor, e para que o professor não se limite a exercer a função prático-utilitária da educação, é preciso preparar.

[...] os indivíduos para saber viver na realidade tal qual ela é, concebendo o ser humano, como ser adaptativo às condições "naturais" postas. Nesse sentido, defendem como um papel precípuo a formação para o trabalho, ou seja, formar indivíduos capazes de se adaptarem às exigências e à transformação no mundo do trabalho em convergência com as demandas do mercado. Isso requer a formação de habilidades e competências para a tomada rápida e eficiente de decisões que sejam úteis ao tipo de atividade que o indivíduo desenvolverá (CARVALHO, 2012).

O tipo de formação desenvolvida é, em parte, devido à "imposição" das políticas públicas educacionais, à formação inadequada ou, então, à falta de qualificação do professor. Nesse contexto, acredita-se na necessidade da diversificação das práticas docentes com vistas à incorporação das Tecnologias de Informação e Comunicação (TIC) como ferramentas auxiliares no planejamento didático das aulas de matemática, em especial, no ensino de Geometria nos anos inicias da educação básica. Diante desse cenário, acredita-se que uma forma de diversificar as práticas docentes partiria da análise e da reflexão das concepções matemáticas dos professores de educação básica em relação ao ensino de Geometria, que podem ser utilizadas como ferramentas auxiliares para fomentar a formação continuada. Ao analisar e refletir sobre o conteúdo dessas concepções, espera-se obter informações que permitirão evoluir na identificação das razões e suas implicações na prática docente. Segundo Freire (1996), "na formação permanente dos professores, o momento fundamental é o da reflexão crítica sobre a prática". A escolha desse tema deve-se a uma curiosidade inicial na utilização das TIC no ensino de Geometria, em especial, sobre como se tem dado o processo de ensinar (e aprender) geometria e, em particular, o tópico quadriláteros, nos anos iniciais do Ensino Fundamental.

Assim, esta pesquisa tem por objetivo analisar e compreender as concepções matemáticas dos professores do $1^{\circ}$ ao $5^{\circ}$ ano do ensino fundamental e, a partir disso, oportunizar a introdução do uso de TIC como ferramentas auxiliares na prática docente, no ensino de quadriláteros. Nessa investigação, buscamos responder o seguinte problema de pesquisa: "De que 
modo a utilização das TIC podem contribuir na organização e para o desenvolvimento da Prática Docente, a partir das Concepções Matemáticas de professores ao desenvolver o ensino do conteúdo Quadriláteros aos alunos do $1^{\circ}$ ao $5^{\circ}$ ano do ensino fundamental?" Para responder ao problema da pesquisa, elaboramos questões de pesquisa que nortearam o desenvolvimento deste trabalho.

- Que políticas públicas são desenvolvidas, com o objetivo de proporcionar uma formação continuada aos professores, na área de matemática, em especial sobre Geometria?

- Como os professores dos anos iniciais do ensino fundamental das escolas da Rede Escolar Pública Municipal (REPM) de uma determinada cidade do interior do Rio Grande do Sul organizam e desenvolvem o ensino de geometria e, em particular, o ensino de quadriláteros?

- Que concepções os professores do $1^{\circ}$ ao $5^{\circ}$ ano do ensino fundamental das escolas da referida REPM apresentam sobre o ensino de quadriláteros?

- Que mudanças aconteceram na organização e no desenvolvimento da prática docente, a partir da participação dos professores dos anos iniciais do ensino fundamental das escolas da REPM no Pacto Nacional pela Alfabetização na Idade Certa (PNAIC) Matemática?

- De que modo as TIC pode contribuir para a organização e desenvolvimento da prática docente dos professores dos anos iniciais do ensino fundamental das escolas da referida REPM ?

A partir da definição do problema de pesquisa, elaboramos referenciais teóricos que proporcionassem procedimentos metodológicos adequados à nossa pesquisa os quais passamos a expor abaixo.

\section{SABERES DOCENTES E A FORMAÇÃO DE PROFESSORES}

Os meios e procedimentos de planejamento, organização e execução da complexa atividade de aprender a ensinar é um constante desafio que leva a questionar: O que os professores precisam saber para poder ensinar e para que seu ensino possa conduzir à aprendizagem dos alunos? Como os professores aprendem a ensinar? Como constroem conhecimentos e saberes sobre o ensino? Para responder a esses questionamentos, é importante iniciar refletindo sobre outras questões:

Quais são os saberes que servem de base ao ofício de Professor? [...] Como esses saberes são adquiridos? [...] Como a formação dos professores, seja na universidade ou noutras instituições, pode levar em consideração e até integrar os saberes dos professores de profissão na formação de seus futuros pares? (TARDIF, 2012). 
[...] no âmbito dos ofícios e profissões, não creio que se possa falar de saber sem relacioná-lo com os condicionantes e com o contexto do trabalho: o saber é sempre o saber de alguém que trabalha alguma coisa no intuito de realizar um objetivo qualquer. [...] o saber dos professores é o saber deles e está relacionado com pessoa e a identidade deles, com a experiência de vida e com sua história profissional, com suas relações com os alunos em sala de aula e com os outros atores escolares na escola, etc. (TARDIF, 2012).

Diante da diversidade de tipologias de saberes docentes, Tardif (2012) propõe um modelo construído a partir das categorias dos próprios docentes e dos saberes que utilizam efetivamente em sua prática profissional cotidiana. Ele percebeu que os professores conferem status maior aos saberes experienciais, pois esses constituem os fundamentos da prática e da competência profissional, e é "impossível compreender a natureza do saber dos professores sem colocá-los em íntima relação com o que os professores, nos espaços de trabalho cotidianos, são, fazem, pensam e dizem" (TARDIF, 2012).

Assim, a prática profissional docente é "um saber plural formado pelo amálgama mais ou menos coerente de saberes oriundos da formação profissional e de saberes disciplinares, curriculares e experienciais" (TARDIF, 2012). Esses saberes estão sintetizados no Quadro 1.

\section{Quadro 1 - Saber, tempo e local de aquisição}

\begin{tabular}{|l|l|}
\hline Saber & Tempo e local de aquisição \\
\hline Saberes da Formação Pro- & Adquirido na formação inicial de professores em "[...] estabele- \\
fissional (das Ciências da & cimentos de formação de professores, os estágios, os cursos de \\
Educação a da Ideologia & $\begin{array}{l}\text { Peciclagem, etc." (TARDIF, 2012) a partir de leituras em aportes } \\
\text { teóricos. }\end{array}$ \\
\hline Saberes Disciplinares & $\begin{array}{l}\text { Adquirido na formação inicial e continuada de professores "são } \\
\text { transmitidos nos cursos e departamentos universitários indepen- } \\
\text { dentemente das faculdades de educação e dos cursos de formação } \\
\text { de professores" (TARDIF, 2012) a partir de Leituras em aportes } \\
\text { teóricos. }\end{array}$ \\
\hline Saberes Curriculares & $\begin{array}{l}\text { Adquirido na formação inicial de professores; em "Programas, } \\
\text { livros didáticos, cadernos de exercícios, fichas, etc." (TARDIF, } \\
\text { 2012), a partir de consulta em documentos e da atuação profissi- } \\
\text { onal. }\end{array}$ \\
\hline Saberes Experienciais & $\begin{array}{l}\text { Adquirido na formação inicial e continuada de professores, na } \\
\text { atuação profissional; na interação com outras pessoas, professores } \\
\text { e alunos; no seu exercício profissional, em diversas instituições, } \\
\text { tais como: família, grupos sociais, escola, sala de aula etc., ou } \\
\text { seja, esse saber é aprendido em tempos sociais diferentes. }\end{array}$ \\
\hline
\end{tabular}

Fonte: Adaptado de Tardif (2012).

Nesse contexto, para formar profissionalmente um professor, há de se garantir o acesso a saberes tanto oriundos do campo da matéria de ensino (disciplinar) como oriundos do campo 
pedagógico (ciências da educação, curricular e pedagógico para o ensino) para que sejam construídos pelos alunos, futuros professores, ao longo da formação inicial. Essa questão acreditase, tem sido um dos pontos frágeis das formas de organização dos currículos dos cursos de licenciatura. Eles têm priorizado ao longo dos anos uma formação pautada majoritariamente nos saberes disciplinares, ou seja, nos saberes de referência para a matéria de ensino ((SHULMAN, 1986); (GAUTHIER, 1998)), desconsiderando que estes são apenas uma parte da formação docente, que se completa com outro conjunto de saberes oriundos do campo pedagógico.

No que se refere à formação de professores, ela é constituída de duas grandes dimensões: a Formação Disciplinar e a Formação Pedagógica. A primeira diz respeito aos Conhecimentos dos Conteúdos de Ensino, aqueles que tratam dos conhecimentos produzidos no campo científico e que são organizados nas diferentes disciplinas nos currículos escolares. A segunda, Formação Pedagógica, se divide em dois grandes grupos de saberes, aqueles referentes ao Conhecimento Pedagógico Geral, que tratam das ciências da educação, e são aqueles conhecimentos profissionais que "embora não o ajudem diretamente a ensinar, informam-no a respeito de várias facetas de seu ofício ou da educação de um modo geral" (GAUTHIER, 1998) e o Conhecimento Pedagógico Específico, que, segundo Shulman (1986), entende-se como o "conhecimento pedagógico do conteúdo". Esse conhecimento vai além dos conteúdos disciplinares, ele se efetiva quando o professor os organiza para o ensino.

Para Shulman (1986), o conhecimento pedagógico da matéria consiste no modo de formular e apresentar o conteúdo de modo a torná-lo compreensível aos alunos. Para isso, é possível incluir analogias, demonstrações, experimentações. É importante também que o professor saiba utilizar diferentes estratégias de ensino. Acredita-se que ele precisa conhecer os recursos e as tecnologias educacionais para poder proporcionar aos seus alunos outras fontes de informação e de conhecimento.

Nessa perspectiva, as novas tecnologias da informação remetem para um tipo de sociedade na qual o conhecimento passou a ser a matéria-prima. Sendo assim, a utilização dessas tecnologias pode contribuir de modo significativo nos processos de aprender a ensinar. Assim, faz-se necessário repensar a formação de professores, em especial, a continuada, frente a esses novos desafios tecnológicos. Nesse sentido, entende-se que a utilização dessas tecnologias no contexto da sala de aula oportuniza ao professor proporcionar estratégias de ensino que favoreçam a participação ativa dos alunos.

Conforme o conhecimento pedagógico do conteúdo foi evoluindo, percebeu-se a necessidade de compreender a utilização pedagógica das tecnologias e ocorreu, assim, um avanço da inserção das TIC no ambiente escolar. Para Palis (2010), houve uma necessidade de repensar o foco da integração de tecnologia no ensino: "da integração definida por qual e quanta tecnologia é empregada para como e por que é usada; da tecnologia propriamente dita para preocupações com o conteúdo ensinado e práticas instrucionais efetivas com a tecnologia”.

Assim, o mesmo autor acrescenta e define que:

Inspirados nas ideias de Shulman, pesquisadores definem o conhecimento tecnológico e pedagógico do conteúdo (TPACK - Technological Pedagogical 
Content Knowledge) como o conhecimento que os professores precisam ter para ensinar com e sobre tecnologia em suas áreas disciplinares e nível escolar de atuação). Inclui questões instrucionais e de gestão de sala de aula, relações entre tecnologia e conteúdo específico, concepções e usos pedagogicamente apropriados da tecnologia. Esse referencial procura capturar algumas das qualidades essenciais do conhecimento do professor requerido para integrar tecnologia no ensino, ao mesmo tempo em que leva em conta a natureza situada, complexa e multifacetada desse conhecimento (PALIS, 2010).

Inicialmente, o conceito TPACK surgiu como TPCK,

[...]para enfatizar que se trata de um pacote total (total package) requerido para integrar verdadeiramente tecnologia, pedagogia e conteúdo, no delineamento do currículo e da instrução destinados a preparar estudantes para pensar e para aprender com tecnologias digitais (PALIS, 2010).

O TPACK foi demonstrado como elo e interseção dos conhecimentos do conteúdo, pedagógico e tecnológico. Mishra e Koehler (2006), baseando-se no conhecimento pedagógico do conteúdo de Shulman (1986), acrescentarama a dimensão tecnológica que evidenciou como diversos tipos de conhecimentos dos professores podem surgir a partir da integração da evolução tecnológica, pedagógica e conhecimento de conteúdo.

Palis (2010) define que "o conhecimento tecnológico [...] inclui a habilidade de aprender e de adaptar-se a uma nova tecnologia". Também abrange habilidades de operar tecnologias específicas, e ainda afirma que o conhecimento tecnológico do conteúdo compreende o impacto de tecnologias nas práticas e conhecimentos de áreas de conteúdo específico. Inclui conhecimentos sobre como o conteúdo a ensinar pode ser modificado pelo uso de uma tecnologia e reciprocamente.

O conhecimento tecnológico pedagógico abrange as potencialidades e as limitações de uma tecnologia particular e como esta pode ser usada no ensino e na aprendizagem. Inclui o conhecimento de como o ensino e a aprendizagem podem mudar como resultado do uso de certa tecnologia e reciprocamente. Compreende como as características de uma tecnologia se relacionam com estratégicas pedagógicas (PALIS, 2010).

Nessa acepção, percebe-se que o conhecimento base vai, além do conhecimento da disciplina, deslocar-se para uma dimensão do conhecimento da disciplina para o ensino. Isso está diretamente relacionado à capacidade que o professor tem de transformar o conhecimento do conteúdo que ele possui em formas que sejam pedagogicamente eficazes e possíveis de adaptação às variações de habilidade e contexto apresentados pelos alunos. Nesse sentido, acredita-se que a experiência de inserção das TIC na escola durante o processo ensino aprendizagem, que envolve em específico um conteúdo matemático, é importante para o professor pensar sobre como agir ou como agiu em sala de aula. Após essa reflexão, ele vai perceber como pode melhorar sua prática docente. 


\section{AS TIC E A FORMAÇÃO DE PROFESSORES}

A sociedade contemporânea produz, reproduz e aceita em compasso acelerado as mudanças e inovações tecnológicas, e transforma-se diariamente. Essas transformações alteram e determinam a forma com que o homem vive, convive e se relaciona com os outros e em sociedade. Segundo Kenski (2007), [...] "com o uso de inovações tecnológicas cada vez mais poderosas, os homens buscavam ampliar seus domínios e acumular cada vez mais riquezas". Os impactos dessas transformações no contexto escolar demandam uma formação contínua dos professores de maneira a conhecer, aprender e (re)aprender como comunicar e ensinar nesses novos tempos. Nesse compasso, acredita-se que a escola deve estar aberta a organizar e planejar novas formas de ensinar que contemplem as potencialidades, os problemas e as necessidades de todos os segmentos da escola, diante da utilização das tecnologias e das suas reais influências no processo de ensino e aprendizagem. Em consonância com essas ideias,

Ensinar e aprender estão sendo desafiados como nunca antes. Há informações demais, múltiplas fontes, visões diferentes de mundo. Educar hoje é mais complexo porque a sociedade também é mais complexa e também o são as competências necessárias. As tecnologias começam a estar um pouco mais ao alcance do estudante e do professor. Precisamos repensar todo o processo, reaprender a ensinar, a estar com os alunos, a orientar atividades, a definir o que vale a pena fazer para aprender, juntos ou separados (MORAN, 2004).

Para Kenski (2007), o fracasso de muitos projetos educacionais que utilizaram as diferentes mídias tais como: rádio, televisão, computador e Internet, nem sempre se deve à incompetência ou má vontade das partes envolvidas. Existem problemas recorrentes que estão em diversos projetos que fracassaram. Nesse contexto, a autora destaca a falta de conhecimento dos professores em como utilizar pedagogicamente as tecnologias, a não adequação da tecnologia ao conteúdo que vai ser ensinado, problemas de ordem técnica e operacional, falta de tempo para formação continuada, formação inicial deficiente, a falta de recursos financeiros para manutenção e atualização de programas, a necessidade de fiscalização da utilização dos computadores e das redes pelos alunos. A autora salienta ainda que é necessário evitar a supervalorização do papel do computador na ação educativa.

A inserção das TIC na educação brasileira evoluiu em ciclos, alicerçados nos avanços tecnológicos, impulsionados ora por políticas públicas de incentivo ora pela necessidade da escola de repensar e potencializar a utilização dessas tecnologias no ensino aprendizagem.

A utilização dessas tecnologias, muitas vezes, causa receio por parte dos professores, mas é preciso lembrar que permitem o crescimento enquanto educadores, bem como revigoram as práticas pedagógicas e tornam as aulas mais atraentes e fundamentadas, desde que bem planejadas e executadas. Nesse contexto, é essencial inovar as práticas pedagógicas, modificar a forma de trabalhar em sala de aula, e admitir que as tecnologias fazem parte do cotidiano dos alunos e que é possível, também, aprender com eles.

Para que os professores utilizem adequadamente as TIC na educação matemática, muitos são os desafios que devem ser superados. Inúmeros são os fatores que poderiam contribuir 
para a formação continuada desses profissionais, tais como a formação por meio de eventos ou cursos, a realização e a participação em oficinas de aprendizagem e a troca de experiências. A formação oferecida tanto aos professores como aos gestores, nas graduações, não é percebida como suficiente e adequada, já que

O tipo de formação inicial que os professores costumam receber não oferece preparo suficiente para aplicar uma nova metodologia, nem para aplicar métodos desenvolvidos teoricamente na prática de sala de aula. Além disso, não se tem a menor informação sobre como desenvolver, implantar e avaliar processos de mudança (IMBERNÓN, 2001).

Portanto, há falta de preparo para o uso da tecnologia focado no processo de ensino e aprendizagem, ou na aprendizagem de conteúdos e no desenvolvimento de competências e habilidades dos alunos. Os cursos de formação continuada para utilização das TIC para os professores preparam, muitas vezes, apenas para a utilização dessas tecnologias.

A utilização das TIC na escola, seus possíveis impactos nas práticas pedagógicas, suas potencialidades e limitações como ferramentas de ensino e aprendizagem não geram mudanças isoladamente. Essas mudanças, para se efetivarem, passam necessariamente pela adequação e reformulação da formação inicial e continuada dos profissionais envolvidos nesse processo, e são eles que vão determinar o sucesso ou fracasso dessa iniciativa. Com a utilização das tecnologias, podem-se estabelecer novas relações para a construção do conhecimento, e proporcionar uma aprendizagem dinâmica e colaborativa aos professores, uma vez que

Recursos didáticos como jogos, livros, vídeos, calculadoras, computadores e outros materiais têm um papel importante no processo de ensino e aprendizagem. Contudo, eles precisam estar integrados a situações que levem ao exercício da análise e da reflexão, em última instância, a base para a formalização matemática (BRASIL, 1997).

Com base nos Parâmetros Curriculares Nacionais (PCN), a matemática deve formar cidadãos capazes de se relacionarem e intervirem na sociedade em que vivem. Devem, assim, ser capazes de resolver problemas práticos do dia a dia, e isso só vai acontecer se eles souberem dominar os recursos tecnológicos a seu favor. Muitas vezes, em sala de aula, os alunos têm uma visão equivocada dos quadriláteros, até mesmo confundindo-os, visto que a maioria dos professores de matemática atém-se à representação usual dos quadriláteros. Esses erros e dificuldades são diagnosticados em diferentes contextos, diferentes ambientes escolares e com diferentes tipos de figuras - como triângulos, retângulos, paralelogramos ou figuras quaisquer (BALTAR; LIMA, 2002).

Nesse sentido, acredita-se que seja necessário fazer com que os alunos percebam a relação entre o que está sendo trabalhado em sala de aula e as necessidades do dia a dia. Sendo assim, é possível estabelecer, na prática, as semelhanças e diferenças entre os quadriláteros a partir dos recursos tecnológicos e ratificá-las depois. Nesse contexto, entende-se que, especialmente no trabalho com geometria, destacam-se os programas de geometria dinâmica. Segundo Santarosa e Gravina (1998), "Os ambientes informatizados apresentam-se como ferramentas de grande potencial frente aos obstáculos inerentes ao processo de aprendizagem." 
Esses ambientes são ferramentas de construção: desenhos de objetos e configurações geométricas são feitos a partir das propriedades que os definem. Através de deslocamentos aplicados aos elementos que compõe o desenho, este se transforma, mantendo as relações geométricas que caracterizam a situação. Assim, para um dado objeto ou propriedade, temos associada uma coleção de "desenhos em movimento", e os invariantes que aí aparecem correspondem às propriedades geométricas intrínsecas ao problema. E este é o recurso didático importante oferecido: a variedade de desenhos estabelece harmonia entre os aspectos conceituais e figurais; configurações geométricas clássicas passam a ter multiplicidade de representações; propriedades geométricas são descobertas a partir dos invariantes no movimento (GRAVINA, 1996).

Assim, identificou-se o software Geogebra como uma ferramenta adequada para superar as dificuldades apresentadas no processo de ensino e aprendizagem de quadriláteros. Sobretudo, porque esse tipo de TIC pode estabelecer novas mediações entre a maneira que o professor aborda o conteúdo, como o aluno compreende e como o conteúdo é apresentado.

\section{ABORDAGEM METODOLÓGICA}

Nesta pesquisa, empregou-se a abordagem qualitativa e os aportes teóricos como guia para a organização e desenvolvimento dos procedimentos metodológicos adotados. Para definir a amostra de pesquisa, inicialmente foi realizado um levantamento do número de escolas existente na REPM. Como resultado desse levantamento inicial, identificou-se que a REPM na referida cidade, possui um total de 11 escolas, sendo oito escolas de Ensino Fundamental Incompleto - Anos Iniciais, uma escola de Educação Infantil, uma escola de Ensino Fundamental Incompleto - Anos Finais e uma escola de Ensino Fundamental Completo, com 27 professores atuando nos anos iniciais do Ensino Fundamental.

Para proceder aos recortes da pesquisa e, assim, definir a amostra, estabeleceu-se o seguinte critério de exclusão: foram selecionadas para participarem da pesquisa apenas as escolas que ofereciam do $1^{\circ}$ ao $5^{\circ}$ ano do Ensino Fundamental (anos iniciais). Dessas escolas, foram sujeitos de pesquisa os professores que participaram do Pacto Nacional pela Alfabetização na Idade Certa (PNAIC) no ano de 2014. A escolha desses sujeitos deve-se à necessidade de identificar como as políticas públicas de formação continuada e de implementação de TIC incidem nas escolas de Educação Básica, uma vez que foi proporcionado aos professores participantes um conjunto de ações que auxiliaram na elaboração de estratégias pedagógicas que poderiam contribuir para a prática docente, com o objetivo de garantir que todas as crianças estivessem alfabetizadas até os oito anos de idade.

Desse modo, os sujeitos que participaram dessa pesquisa foram 12 professoras de Educação Básica da REPM, atuantes no ensino fundamental e participantes do PNAIC/2014. Por razões de confidencialidade, as professoras participantes desta pesquisa foram identificadas com a sigla PEFAI - Professor Ensino Fundamental Anos Iniciais. A numeração de 01 a 12 foi utilizada para identificá-las e obedeceu a uma listagem aleatória previamente organizada. As 
entrevistas e as informações obtidas a partir dos questionários foram analisadas com o intuito de encontrar respostas às questões e ao problema de pesquisa.

O Espaço de Interação social pesquisado foi a Oficina de Formação Continuada de Professores de Educação Básica, desenvolvida para a realização da pesquisa, onde foram utilizados os seguintes instrumentos: entrevista, questionário e observação.

A oficina, que foi o principal espaço de pesquisa, foi oferecida aos professores das escolas da REPM de um município do interior do Rio Grande do Sul e teve como objetivo proporcionar, por meio de atividades, uma prática docente alternativa utilizando o software Geogebra, a fim de enriquecer o Ensino de Quadriláteros nos anos iniciais do Ensino Fundamental.

A referida oficina teve como título "O software Geogebra na Formação Continuada de Professores no Ensino Aprendizagem de Quadriláteros", e os assuntos básicos tratados foram: polígonos, ângulos e quadriláteros (definições, características e propriedades). O tempo previsto para realização da oficina foi de oito horas. As atividades foram realizadas no Laboratório de Informática da Escola Estadual de Ensino Médio da cidade. A oficina contou com a participação de 12 professoras da REPM. As atividades abordadas foram elaboradas a partir da análise das respostas das professoras na entrevista. Os subsídios para a elaboração das atividades da oficina foram baseados em materiais criados por Amâncio e Gazire (2015) e Nasser e Sant' anna (2004), pois esses materiais, após algumas adaptações (como por exemplo, a inserção do software Geogebra), ofereceram um conjunto de atividades do tipo exploratórias, que possibilitam a sistematização das definições dos quadriláteros, identificando as suas características e propriedades.

\section{ANÁLISE E DISCUSSÃO DOS RESULTADOS}

Os próximos parágrafos apresentam os resultados construídos a partir da análise das informações coletadas mediante a utilização dos instrumentos de pesquisa. Para realizar essa análise, foi feita a transcrição de entrevistas realizadas e as respostas dos questionários aplicados. Na segunda parte da pesquisa, foi realizada a observação da implementação de uma oficina de formação continuada de professores do ensino fundamental da REPM.

Constatou-se que, no tocante à formação inicial das professoras, quase a totalidade (9/12) é licenciada em Pedagogia. Entre as demais, uma é licenciada em espanhol e com formação de nível médio modalidade normal, uma com formação de nível médio modalidade normal e uma apenas com ensino fundamental completo. Nesse contexto, destaca-se a influência dessa formação no exercício da docência dos professores, uma vez que,

\footnotetext{
Além dos saberes produzidos pelas ciências da educação e dos saberes pedagógicos, a prática docente incorpora ainda saberes sociais definidos e selecionados pela instituição universitária. Estes saberes integram-se igualmente à prática docente através da formação (inicial e contínua) dos professores nas diversas disciplinas oferecidas pela universidade (TARDIF, 2012).
}

As entrevistas e as informações obtidas a partir dos questionários foram analisadas com 
o intuito de encontrar respostas às questões e ao problema de pesquisa. No que se refere ao desenvolvimento do ensino de matemática na sua formação inicial, a maioria das professoras (09/12) disse que existe uma relação entre a teoria e a prática, com ênfase para os jogos e o material concreto.

A respeito da participação das professoras em Cursos/Oficinas de Formação Continuada, nos últimos cinco anos, conclui-se que participaram somente do PNAIC/2014 e das formações promovidas pela Secretaria Municipal de Educação, Cultura, Desportos e Eventos (SMECDE) do município, anualmente, no início do ano letivo e, eventualmente, no recesso do mês de julho.

Em relação à participação em Curso/Oficina de Formação Continuada na área de matemática, mais especificamente na área de geometria, todas as professoras participaram apenas do PNAIC 2014 - Matemática.

A maioria das professoras participantes da pesquisa (08/12) atua em uma única escola e tem experiência profissional de, em média, 14 anos na REPM do $1^{\circ}$ ao $5^{\circ}$ do Ensino Fundamental e apenas uma delas apresenta experiência fora dessas séries. Ao analisar as respostas das professoras referentes à importância do ensino da matemática nos anos iniciais do ensino fundamental, destacam-se as falas abaixo, que reproduzem essa premissa:

A matemática me ajuda a alfabetizar,[...] a matemática tem o papel tão importante quanto o sistema fonético.(PEFAI 01).

É muito importante, pois a matemática sendo bem trabalhada nos anos iniciais, a criança vai ter o gosto por ela e não irá encarar como uma coisa de outro mundo. (PEFAI 10)

Com o ensino da matemática, o educando poderá compreender melhor as relações consigo mesmo e com o mundo; aprendendo a orientar-se no espaço, ordenar, quantificar e operar quantidades, medir, apreciar, classificar, combinar e utilizar formas. Desenvolver o raciocínio lógico. (PEFAI 12)

É muito importante, pois é o dia a dia que convivemos com a matemática, desde a hora que levantamos até a hora que vamos dormir. Matemática é vida. (PEFAI 09)

Assim, salienta-se a importância do ensino da matemática nos anos iniciais do ensino fundamental, com vistas à construção de novas perspectivas para a prática pedagógica. A disciplina deve ser utilizada como meio para a compreensão e a transformação do processo educativo de maneira que possa ser uma ferramenta de auxílio na construção do processo pedagógico.

Ao analisar as respostas ao questionamento sobre a importância do ensino da geometria nos anos iniciais do ensino fundamental, constatou-se que a maioria das professoras (10/12) ressalta que a Geometria deve ser ensinada nesse período. Entretanto, não determinam um ano específico para que comece o ensino da geometria, visto que, segundo a PEFAI 08 "isso depende do ano que estou atuando, uma vez que, para cada ano, o ensinamento e aprofundamento do conteúdo é diferente". Pôde-se observar que, em geral, quando as professoras trabalham o ensino da geometria, trabalham a partir de material concreto, blocos lógicos, formas, jogos e observações. Ao estabeleceram uma relação da Geometria com os outros conteúdos/disciplinas, elas utilizam as noções básicas das formas na educação artística, as noções de espaço a partir das maquetes e mapas na geografia e a grafia correta das palavras no português. Ao examinar 
as respostas das professoras com relação às concepções sobre quadriláteros, percebeu-se que as docentes não apresentam um conhecimento claro com relação a esse aspecto, suas características e definições, conforme apresentado no Quadro 2.

\section{Quadro 2 - Concepções iniciais das Professoras sobre Quadriláteros}

\begin{tabular}{|c|c|}
\hline Tópico & finição e Caracterização das Professoras \\
\hline Quadriláteros & $\begin{array}{l}\text { - Figura cujos ângulos são retos (PEFAI 06); } \\
\text { - São polígonos com linhas fechadas que não se cruzam (PEFAI 08); } \\
\text { - Figura Plana com } 4 \text { lados (PEFAI 10); } \\
\text { - Tem quatro lados congruentes (PEFAI 09). }\end{array}$ \\
\hline Quadrado & $\begin{array}{l}\text { - Tem quatro lados congruentes (PEFAI 02); } \\
\text { - São polígonos de quatro lados iguais com ângulos retos de } 90 \\
\text { o com ângulos internos retos (PEFAI 08); } \\
\text { - Figura Plana com } 4 \text { lados iguais (PEFAI 10); } \\
\text { - Quadrilátero com } 4 \text { lados congruentes (PEFAI 07). }\end{array}$ \\
\hline Retângulo & $\begin{array}{l}\text { - } 2 \text { lados com medidas iguais e } 2 \text { com medidas diferentes (PEFAI 07); } \\
\text { - Figura que possui ângulos retos (PEFAI 03); } \\
\text { - Quadrilátero com } 4 \text { ângulos retos (PEFAI 12); } \\
\text { - São polígonos com linhas fechadas que não se cruzam (PEFAI 08). }\end{array}$ \\
\hline Paralelogramo & $\begin{array}{l}\text { - Possui } 2 \text { lados congruentes e } 2 \text { adjacentes (PEFAI 07); } \\
\text { - Quadrilátero plano cujos lados opostos são paralelos (PEFAI 06); } \\
\text { - Figura plana cujos lados opostos são paralelos (PEFAI 05); } \\
\text { - São polígonos que possuem lados congruentes/paralelos (PEFAI 08). }\end{array}$ \\
\hline Losango & $\begin{array}{l}\text { - Dois lados iguais e um diferente (PEFAI 07); } \\
\text { - Tem dois lados congruentes e } 2 \text { com medidas diferentes (PEFAI 09); } \\
\text { - Quadriláteros com dois lados paralelos desiguais (PEFAI 06); } \\
\text { - Quadrilátero que tem } 2 \text { lados opostos paralelos (PEFAI 12). }\end{array}$ \\
\hline
\end{tabular}

\section{Fonte: Dados da pesquisa.}

Nesse contexto, percebe-se que as definições e caracterizações das professoras sobre quadriláteros são insuficientes e restritas ao senso comum. Isso contradiz o que é esperado, pois segundo Shulman $(1986,1987)$ o professor deve compreender a disciplina que ministra a partir de diferentes perspectivas e deve saber estabelecer relações entre tópicos do conteúdo disciplinar. Ao serem questionadas sobre as formas que organizam e desenvolvem o ensino de quadriláteros, as professoras relataram que utilizam tangram, blocos lógicos, atividades lúdicas, material dourado e jogos. Quanto à abordagem que o livro didático adotado faz com relaçãao tópico quadriláteros, a maioria das professoras (9/12) mostrou-se satisfeita com a maneira como foi abordado. Esse tópico foi tratado de forma simples e adequada à percepção dos alunos, pois, segundo elas, acontece a partir da representação das figuras. Com base nas diversas falas, é possível afirmar que a maioria das professoras (8/12) diz não apresentar dificuldades na sua prática com relação ao ensino de quadriláteros, apesar de suas concepções a cerca desse conteúdo serem frágeis. Com relação à utilização das TIC, em especial de materiais interativos (softwares 
ou objetos de aprendizagem), na organização e no desenvolvimento da sua prática docente ao ensinar Geometria, principalmente no que se refere a quadriláteros, a maioria das professoras destacou a importância da utilização das TIC como recurso auxiliar no ensino de geometria, em especial quadriláteros, nos anos iniciais do ensino fundamental.

Na sequência, estão descritas duas das dez atividades realizadas na Oficina de Formação Continuada. Na realização dessa oficina, era esperado alcançar alguns objetivos, tais como: Identificar e compreender as diferentes concepções dos professores sobre quadriláteros; Identificar e Compreender as diferenças e semelhanças entre os quadriláteros; Classificar quadriláteros de acordo com as suas características; Elaborar sínteses a partir de discussões coletivas realizadas. No início, foram apresentados os objetivos da oficina e o recurso que seria utilizado em algumas das atividades propostas, o software de Geometria Dinâmica Geogebra, sua interface e a funções dos principais comandos

O objetivo principal da oficina foi proporcionar uma prática docente alternativa, com a utilização de diferentes tecnologias, em especial o software Geogebra, a fim de enriquecer o Ensino de Quadriláteros nos anos iniciais do Ensino Fundamental. O material elaborado para realização dessa oficina contou com uma apostila, arquivos digitais nos formatos .pdf (Portable Document Format) e .ggb (documentos criados com o uso do programa GeoGebra). A primeira atividade teve os seguintes objetivos: Identificar características comuns e diferentes em diversas figuras planas; Compreender que as figuras podem ser classificadas de acordo com critérios variados e Conceituar polígonos. Nessa atividade, as professoras abriram um arquivo previamente construído no software Geogebra e observaram a coleção de figuras e as separaram de acordo com as seguintes características: Os lados são segmentos de reta; As figuras são fechadas e lados ou linhas não se cruzam. Após a separação das figuras, elas responderam às seguintes questões: Quais as figuras que apresentam as três características e como podemos chamá-las? As figuras que você selecionou são todas iguais? O que elas têm em comum? Quais as diferenças entre elas? Após essa atividade, as professoras reuniram-se em duplas e trocaram ideias para escreverem as características de um polígono e de um não polígono. A maioria das professoras participantes da oficina identificou que as figuras que possuíam as três características: "Os lados são segmentos de reta, figuras fechadas e lados ou linhas não se cruzam", eram "quadriláteros". Acredita-se que essa identificação se deu por estar relacionada ao desconhecimento ou esquecimento da definição de polígonos e pela indução provocada pela temática da oficina.

Após a discussão das respostas dadas pelas professoras na realização da primeira atividade, elas perceberam que essas três características eram comuns a um grupo de figuras, simultaneamente, e que essas figuras eram chamadas de polígonos. Consequentemente, ao caracterizarem e conceituarem os polígonos, elas, automaticamente, definiram os não polígonos como as figuras que não tinham essas três características ao mesmo tempo. Também foram realizadas atividades sobre ângulos, convexidade, classificação de quadriláteros, totalizando nove atividades. Cabe destacar a penúltima atividade realizada que teve como objetivo identificar as características que diferem os principais quadriláteros. Para isso, as professoras abriram um arquivo no Geogebra, conforme ilustra a Figura 1. 


\section{Figura 1 - Atividade realizada no GeoGebra}

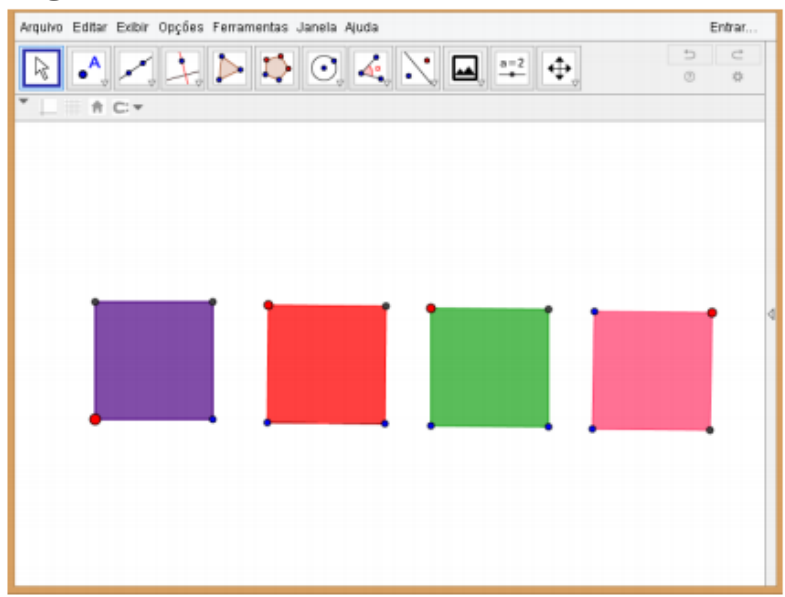

Fonte: Dados da pesquisa.

Foi solicitado, então, que elas movimentassem o ponto vermelho do primeiro quadrilátero e destacassem o que elas observavam, e assim sucessivamente, para os demais quadrados. Ao movimentar os pontos vermelhos em cada um dos quadriláteros, esperava-se que os professores percebessem que o quadrilátero lilás é sempre um quadrado, e apenas um quadrado, ou seja possui todos os lados congruentes e todos os ângulos retos, como ilustra a Figura 2.

Figura 2 - Atividade dinâmica realizada no GeoGebra (Parte 1)

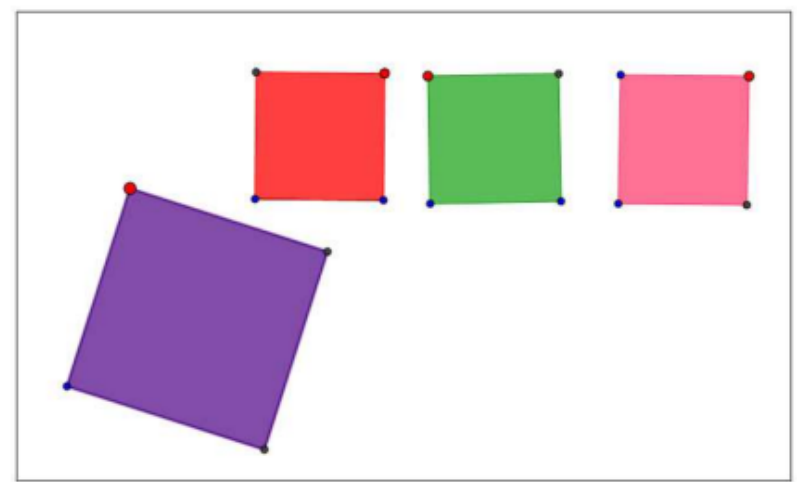

Fonte: Dados da pesquisa.

O quadrilátero vermelho, apesar de inicialmente ter o formato de um quadrado, foi construído como um retângulo, ou seja ao movimentar o ponto vermelho, seus lados modificavam de tamanho (dois a dois), mas os ângulos permanciam retos, conforme Figura 3.

\section{Figura 3 - Atividade dinâmica realizada no GeoGebra (Parte 2)}

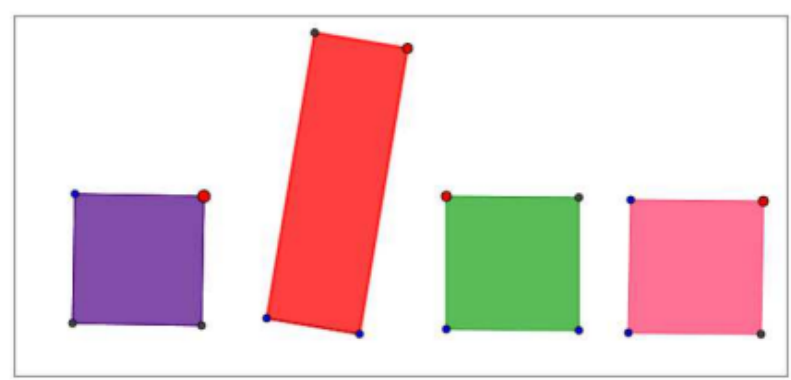

Fonte: Dados da pesquisa.

Do mesmo modo, o quadrilátero verde inicialmente com o formato de um quadrado, ao ser "modificado"via o ponto vermelho, tranforma-se em um paralelogramo, ou seja, possui 
lados opostos paralelos, e o ângulos não são necessariamente retos, como ilustra a Figura 4.

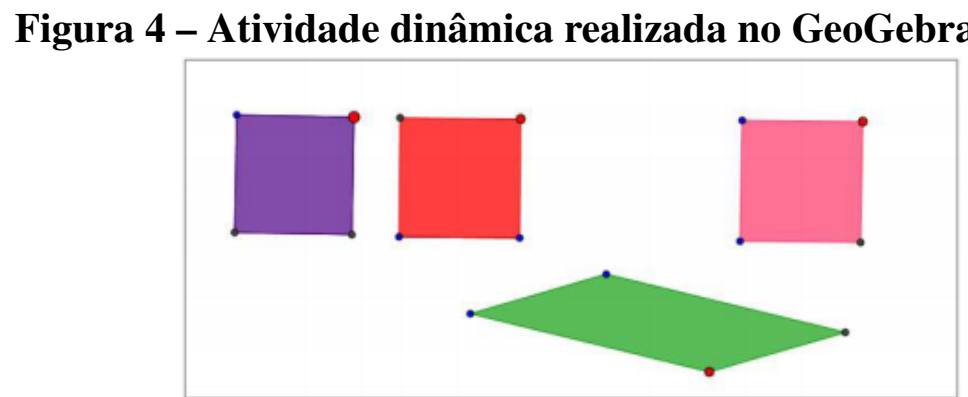

Fonte: Dados da pesquisa.

O quarto quadrilátero (rosa), que possui, inicialmente, o mesmo formato que os demais (quadrado) foi construído com as propriedades inerentes a um losango (todos os lados congruentes), e ao movimentar o ponto vermelho, os ângulos deixam de ser retos (Figura 5).

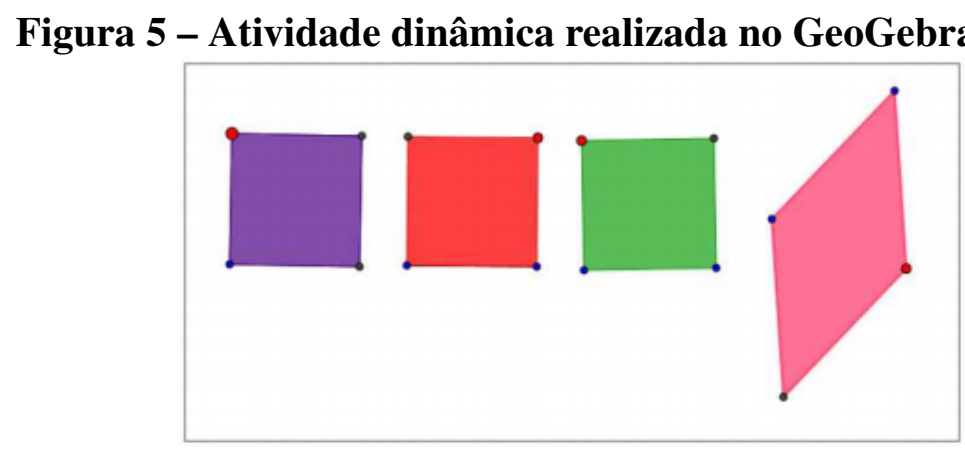

Fonte: Dados da pesquisa.

Algumas professoras apresentaram dificuldade em analisar o que ocorreu com os quadrados ao movimentar o ponto vermelho. Foi questionado quais propriedades eram inerentes aos quadrados e porque mudavam de forma. Durante o período inicial da atividade, elas não conseguiam perceber exatamente o que estava acontecendo com cada uma das figuras e sistematizar essas observações por meio de conclusões. A principal conclusão para essa atividade é que o quadrado é um paralelogramo que possui os quatro lados conguentes (como o losango) e os quatro ângulos retos (como o retãngulo) e, por esse motivo, os quadrados também são paralelogramos, losangos e retângulos.

\section{CONCLUSÃO}

Apresentar conclusões para esta pesquisa leva a analisar alguns aspectos que conduziram seu desenvolvimento. O objetivo estabelecido para a investigação foi o de analisar e compreender as concepções matemáticas dos professores, e assim, proporcionar oportunidades de introduzir a utilização das TIC como ferramentas auxiliares da prática docente dos professores atuantes nos anos iniciais do ensino fundamental, no ensino e aprendizagem de quadriláteros.

Constatou-se que, em geral, as professoras das escolas da REPM do município pesquisado, quando organizam e desenvolvem o ensino de geometria e, em particular, o ensino de 
quadriláteros, trabalham com material concreto, blocos lógicos, formas e jogos. Ao estabeleceram uma relação interdisciplinar da Geometria com os outros conteúdos/disciplinas, essas relações ocorrem com a educação artística, com a geografia e com o português. Detectou-se, também, certa mudança na prática dessas professoras após a participação no PNAIC/2014 Matemática, pois relataram que, após essa participação, enxergaram a matemática como mais prazerosa e que existiam outros recursos disponíveis para auxiliar a sua prática docente. Entretanto, elas não citam a utilização das TIC como recursos didáticos do processo de ensino e aprendizagem de quadriláteros.

Com base nas diversas falas, pode-se afirmar que as concepções das professoras sobre quadriláteros eram insuficientes ou, então, apresentavam lacunas, para que fosse desenvolvido um processo de ensino e aprendizagem de maneira adequada. Isso se deve, em parte, a alguns fatores identificados no decorrer da pesquisa. O principal fator identificado foi com relação à Formação Inicial das professoras, que se acredita ser insuficiente na área de matemática. Todas as professoras participantes desta pesquisa têm formação inicial com pouca ênfase no ensino e aprendizagem de matemática. Acredita-se que seja em decorrência disso que elas apresentam lacunas com relação aos saberes disciplinares.

De modo geral, os sujeitos da pesquisa mostraram-se conscientes da importância do ensino da matemática e da geometria nos anos iniciais do ensino fundamental, porém essa consciência esbarra em dificuldades decorrentes da sua formação inicial e continuada, na falta de infraestrutura e na multisseriação na maioria das escolas. Em relação à formação continuada realizada com as professoras dos anos iniciais do ensino fundamental, pode-se afirmar que ela possibilitou um espaço de discussão e reflexão crítica sobre a prática a partir das atividades propostas. Percebeu-se, no desenvolvimento da Oficina, que "os saberes das disciplinas e os saberes curriculares que os professores possuem e transmitem não são o saber dos professores nem o saber docente"(TARDIF, 2012).

O desenvolvimento deste trabalho permitiu perceber que, mesmo com todas as possibilidades de contribuições das TIC no processo de ensino e aprendizagem, o professor ainda é o protagonista das mudanças, não somente no ensino de geometria, mas também de toda a matemática. Sendo assim, cabe a ele reconhecer, utilizar e avaliar os saberes necessários à sua prática docente, estabelecer relações das TIC com essa prática e o seu papel na organização e no desenvolvimento de maneira a contribuir e transformar a aprendizagem dos sujeitos.

Além disso, percebeu-se, por meio da realização da Oficina, que as TIC, em particular o software Geogebra, podem contribuir de maneira efetiva para organização e desenvolvimento da prática docente, e oferecer técnicas alternativas que enriquecem o ensino de Quadriláteros nos anos iniciais do Ensino Fundamental. É importante salientar que, com esta pesquisa, o objetivo não era finalizar ou determinar as formas de organização e desenvolvimento da prática docente no ensino e aprendizagem de quadriláteros mediados pelas tecnologias e, sim, apresentar e debater atividades alternativas para essa abordagem de geometria nos anos iniciais do ensino fundamental. 


\section{REFERÊNCIAS}

AMâNCIO, Roselene Alves; GAZIRE, Eliane Scheid. O desenvolvimento do pensamento geométrico e as contribuições dos recursos didáticos no estudo dos quadriláteros. Vidya, v. 35, n. 2, p. 16, 2015.

BALTAR, Paula M.; LIMA, Paulo Figueiredo. Um estudo da noção de grandeza e implicações no ensino fundamental. Natal: SBHM, 2002.

BRASIL, Secretaria de Educação Fundamental. Parâmetros curriculares nacionais. Brasília: MEC/SEF, v. 1998, p. 2000, 1997.

CARVALHO, Saulo Rodrigues. A educação e o discurso prático-utilitário do capitalismo contemporâneo. Revista Espaço Acadêmico, v. 12, n. 138, p. 73-82, 2012.

FREIRE, Paulo. Pedagogia da autonomia: saberes necessários à prática docente. São Paulo: Paz e Terra, 1996.

GAUTHIER, Clermont et al. Por uma teoria da pedagogia: pesquisas contemporâneas sobre o saber docente. Ijuí: Unijuí, p. 20, 1998.

GRAVINA, Maria Alice. Geometria dinâmica: uma nova abordagem para o aprendizado da geometria. Anais do VII Simpósio Brasileiro de Informática na Educação, v. 1, p. 1-13, 1996.

IMBERNÓN, Francisco. Formação docente e profissional: formar-se para a mudança e a incerteza. São Paulo: Cortez, 2001.

KENSKI, Vani Moreira. Educação e tecnologias. Campinas: Papirus, 2007.

MISHRA, Punya; KOEHLER, Matthew J. Technological pedagogical content knowledge: A framework for teacher knowledge. Teachers college record, Blackwell Publishing Ltd, v. 108, n. 6, p. 1017, 2006.

MORAN, José Manuel. Os novos espaços de atuação do educador com as tecnologias. Conhecimento local e conhecimento universal: diversidade, mídias e tecnologias na educação. Curitiba: Champagnat, p. 245-253, 2004.

NASSER, Lilian; SANT'ANNA, Neide da Fonseca Parracho. Geometria segundo a teoria de van hiele. Projeto Fundão, 2004.

PALIS, Gilda de La Rocque. O conhecimento tecnológico, pedagógico e do conteúdo do professor de matemática. Educação Matemática Pesquisa, Pontifícia Universidade Catoílica de São Paulo PUC-SP, Programa de Estudos Pós-Graduados em Educação Matemática, v. 12, n. 3, 2010.

SANTAROSA, Lucila Maria A.; GRAVINA, M. Aprendizagem da matemática em ambientes informatizados. In: IV Congresso RIBIE. Brasília: UFRGS, 1998.

SHULMAN, Lee. Knowledge and teaching: Foundations of the new reform. Harvard educational review, Harvard Education Publishing Group, v. 57, n. 1, p. 1-23, 1987.

SHULMAN, Lee S. Those who understand: Knowledge growth in teaching. Educational researcher, Sage Publications Sage CA: Thousand Oaks, CA, v. 15, n. 2, p. 4-14, 1986. 
TARDIF, Maurice. Saberes docentes e formação profissional. Rio de Janeiro: Editora Vozes Limitada, 2012. 